\title{
ULTRA-FINE GRAINED BULK STEEL PRODUCED BY ACCUMULATIVE ROLL-BONDING (ARB) PROCESS
}

\author{
N. Tsuji,* Y. Saito, H. Utsunomiya and S. Tanigawa** \\ Department of Materials Science and Engineering, Osaka University, 2-1 Yamadaoka, Suita, \\ Osaka, 565-0871, Japan \\ (Received December 22, 1998) \\ (Accepted January 7, 1999)
}

\section{$\underline{\text { Introduction }}$}

Much attention has been directed recently to ultra-grain refining of metallic materials, where the grain size is reduced to less than $1 \mu \mathrm{m}$. It is expected that submicrometer grained structure would result in high strength and toughness at ambient temperature [1] as well as high strain rate or low temperature superplasticity at elevated temperatures [2,3]. It has been reported recently that ultra-fine grains can be obtained by intense plastic straining [4]. Several special intense straining processes, such as Torsion Straining (TS) [5-10], Equal-Channel Angular Pressing (ECAP) [8-12] and Mechanical Milling (MM) of powder metals [13-15], have succeeded in producing ultra-fine grains. On the other hand, the disadvantage of these processes is that they are not applicable to large bulk materials. Not small functional materials but large structural materials do require high strength and toughness. From this critical viewpoint, we have recently developed a novel intense straining process for bulk materials, named Accumulative Roll-Bonding (ARB) [16]. We firstly tried to apply ARB to the aluminum alloys, and the bulk sheets with ultra-fine grains whose grain sizes are several hundred nano-meters were successfully produced [17,18]. The ARBed aluminum alloys with ultra-fine grains showed large strength at ambient temperature, which is up to 3.7 times larger than that of the starting materials $[17,18]$. Further, it has been also clarified that the ARBed Al-Mg alloy sheet with submicrometer grains shows low-temperature superplasticity at $473 \mathrm{~K}$ which is half the melting temperature of the material [19]. The purpose of the present study is to clarify whether or not it is possible to produce the bulk steel sheets with ultra-fine grains by ARB process. Because steel is the most useful structural material, the ultra-grain refining of steel is greatly desired. The ultra-grain refining and resulted strengthening of steels could largely reduce the weight of any constructions, and the strengthening without alloying elements would be preferable for recycling. However, no investigation concerning the intense straining of bulk steels has been carried out by now possibly due to the difficulty in processing, although limited results about small materials, such as grain refining by powder metallurgical process (MM) [13-15] or TS of thin discs [7], have been reported.

\footnotetext{
*To whom all correspondence should be addressed. Now visiting at Department of Metallurgical and Materials Engineering, Colorado School of Mines, Golden, CO 80401-1887, USA, tsuji@mat.eng.osaka-u.ac.jp.

**Undergraduate student of Osaka University.
} 


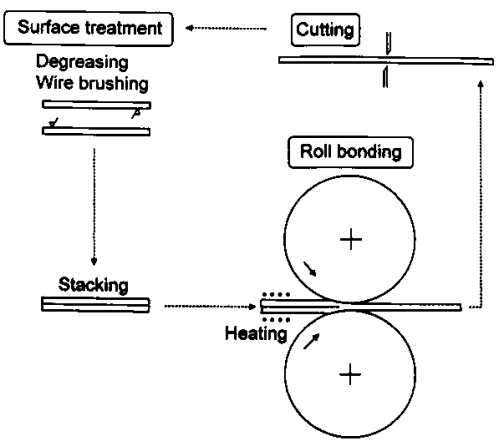

Figure 1. Schematic illustration showing the principle of Accumulative Roll-Bonding (ARB) process.

\section{$\underline{\text { Experimental }}$}

Figure 1 illustrates the principle of ARB process. Although rolling is the most advantageous deformation process for continuous production of bulk sheets, the total reduction in thickness, i.e., the total strain achieved, is limited because of the decrease in the strip thickness with increasing the reduction. In ARB, the rolled material is cut, stacked to be the initial thickness and rolled again. Therefore, the achieved strain is unlimited in this process because repetition times are endless in principle. In order to obtain the bulk material, the stacked sheets are bonded during rolling simultaneously. That is, the rolling in ARB is not only a deformation process but also a roll-bonding process. To achieve good bonding, surface treatments, such as degreasing and wire-brushing, of the sheet surface are done before stacking. Rolling at elevated temperature is advantageous for joinability and workability, though too high temperature would cause recrystallization and cancel the accumulated strain. Therefore, the rolling (roll-bonding) in ARB is preferably carried out at "warm" temperatures.

The material used in this study is a Ti-added interstitial free (IF) steel [20] whose chemical composition is shown in Table 1. Because IF steel scarcely has solute $\mathrm{C}$ and $\mathrm{N}$, the blue-brittleness during rolling at warm temperatures can be avoided. Further, the IF steel is also a very important commercial material as thin sheets. Cold-rolled and fully annealed IF-steel sheets $1 \mathrm{~mm}$ thick, $20 \mathrm{~mm}$ wide and $300 \mathrm{~mm}$ long were provided for ARB process. The mean grain size in the starting sheet was $27 \mu \mathrm{m}$. ARB was conducted under the conditions that the reduction in thickness per cycle was $50 \%$ (equivalent strain of 0.8 ) and the rolling temperature was $773 \mathrm{~K}$. Two pieces of the sheets were stacked to be $2 \mathrm{~mm}$ in thickness, held in an electrical furnace set at $773 \mathrm{~K}$ for 600 s to homogenize the temperature, and then rolled. The sheets were cooled by water after roll-bonding. The surfaces to be joined were degreased and wire-brushed before stacking. The rolling was done by one pass without lubricant using a two-high mill whose roll diameter is $310 \mathrm{~mm}$. The roll peripheral speed was $43 \mathrm{~m}$ $\min ^{-1}$, so that the mean strain rate was $46 \mathrm{~s}^{-1}$. The rolled sheets $1 \mathrm{~mm}$ thick was cut off into two pieces with the size similar to the starting material, and then the above procedures were repeated up to 7 cycles (equivalent strain of 5.6). The $50 \%$ reduction at $773 \mathrm{~K}$ was quite enough to bond the sheets and no fracture at bonded boundaries was observed during experiments. Though edge-cracks of the sheets

TABLE 1

Chemical Composition of the IF Steel (mass\%).

\begin{tabular}{ccccccccc}
\hline $\mathrm{C}$ & $\mathrm{Si}$ & $\mathrm{Mn}$ & $\mathrm{P}$ & $\mathrm{S}$ & $\mathrm{Ti}$ & $\mathrm{B}$ & sol.Al & $\mathrm{Fe}$ \\
\hline 0.0031 & $<0.01$ & 0.15 & 0.010 & 0.005 & 0.049 & $<0.0001$ & 0.054 & bal. \\
\hline
\end{tabular}




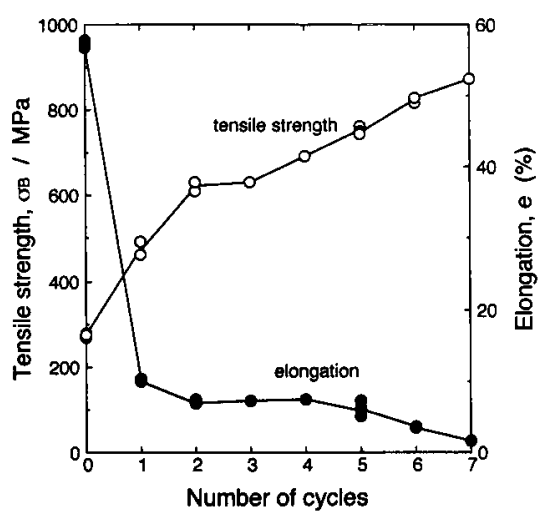

Figure 2. Mechanical properties at ambient temperature of the IF steel after various cycles of ARB at $773 \mathrm{~K}$.

sometimes appeared during rolling after several cycles, satisfactory sheets were obtained in most cases even after 7 cycles of ARB.

Tensile specimens $10 \mathrm{~mm}$ in gage length and $5 \mathrm{~mm}$ in gage width were spark-machined from the ARBed sheets. Tensile direction was parallel to the rolling direction. Tensile tests at ambient temperature were carried out using an instron-type machine at a cross-head speed of $0.5 \mathrm{~mm} \mathrm{~min}{ }^{-1}$, corresponding to a nominal strain rate of $8.3 \times 10^{-4} \mathrm{~s}^{-1}$. The microstructural observation by transmission electron microscopy (TEM) was done for the specimens after ARB. Thin foils parallel to the rolling plane were prepared by twin-jet electro-polishing using a $50 \mathrm{ml} \mathrm{HClO}_{4}+450 \mathrm{ml} \mathrm{CH}_{3} \mathrm{COOH}$ solution, so that the observed position is about $100 \mu \mathrm{m}$ below surface. Hitachi $\mathrm{H}-800$ electron microscope was operated at $200 \mathrm{kV}$.

\section{$\underline{\text { Results and Discussions }}$}

Figure 2 shows the change in mechanical properties at ambient temperature of the ARBed IF steel. The tensile strength increased with increasing strain. It reached $870 \mathrm{MPa}$ after 7 cycles. This is 3.1 times larger than that of the starting material $(280 \mathrm{MPa})$. The tensile strength still tends to increase after 7 cycles. On the other hand, the elongation largely decreased from $57 \%$ to $10 \%$ by 1 cycle of ARB. It kept, however, constant value of about $9 \%$ until 4 cycles, and then decreased slightly with increasing the strain. Such a change in mechanical properties by ARB is quite similar to that in aluminum alloys $[17,18]$.

Figure 3 shows the TEM microstructures of the IF steel after various cycles of ARB. The selected area diffraction $(\mathrm{SAD})$ patterns were taken from the center of the bright field images using an aperture with a diameter of $1.6 \mu \mathrm{m}$. The SAD pattern in Fig. 3(a) after one cycle of ARB (50\% reduction) shows a single net pattern, which indicates that the area scarcely has misorientation. Dislocation cell structure or less-developed subgrains are observed. Whole the specimen shows such a cell or subgrain structure with small misorientation. The specimen after 2 cycles (75\% reduction) showed similar subgrain structure to that in Fig. 3(a). After 3 cycles of ARB (87.5\% reduction), fine grains whose diameters are less than $1 \mu \mathrm{m}$ partly appeared as was shown in Fig. 3(b). The SAD pattern in Fig. 3(b) indicates the evolution of large local misorientations. However, most of the specimen still had subgrain structure with small misorientations at this stage. After 4 cycles of ARB, the fraction of the ultra-fine grains with large misorientation increased with increasing the strain. The most part of the specimens are filled with the ultra-fine grains with large misorientations after 7 cycles of ARB (99.2\% reduction) (Fig. 3(d)), 

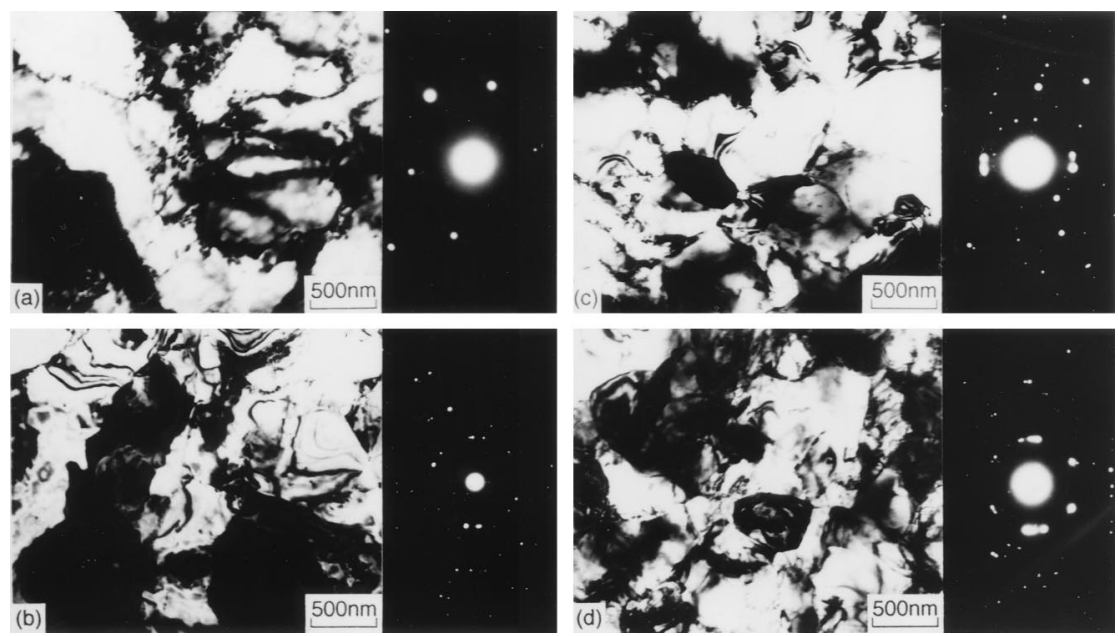

Figure 3. TEM microstructures and corresponding SAD patterns of the IF steel after various cycles of ARB at $773 \mathrm{~K}$. (a) After 1 cycle (50\% reduction, true strain of 0.8$)$. (b) 3 cycles $(87.5 \%$ reduction, true strain of 2.4$)$. (c) 6 cycles $(98.4 \%$ reduction, true strain of 4.8$)$. (d) 7 cycles $(99.2 \%$ reduction, true strain of 5.6).

although subgrain structure still remained in part. Such a microstructural evolution by ARB is similar to that of the aluminum alloys, especially Al-Mg alloy [17]. Further, the increase in the tensile strength (Fig. 2) corresponds well with the increase in volume fraction of the ultra-fine grains, which indicates that the large strength of the ARBed material is mainly due to ultra-grain refining.

It was clarified in this study, anyway, that it is possible to strain highly the bulk steel and to realize the bulk steel sheets with ultra-fine grains by ARB process. Figure 4 shows the typical ultra-fine grains in the ARBed pure aluminum (a), Al-Mg alloy (b) and the present IF-steel (c). It can be seen that the feature of the ultra-fine grains is very similar regardless of material. They show equi-thickness fringes at their boundaries, but the boundaries show irregular shapes. It has been reported that the grain boundaries of the ultra-fine grains produced by intense straining process have non-equilibrium structures $[9,21]$, and it is very likely that the ultra-fine grains produced by ARB have the similar structure as well. It is an interesting result that the microstructural evolution during ARB and the resulted ultra-fine grains are almost the same independent of the kind of materials. However, it should be noted that the mean grain sizes largely differ depending on the materials. The mean grain sizes for 1100 pure aluminum (a), 5083 Al-Mg alloy (b) and IF-steel (c) are $670 \mathrm{~nm}, 280 \mathrm{~nm}$ and $420 \mathrm{~nm}$, respectively. Though the reason of this difference has not been clarified, the grain size must depend on the degree of accumulation of strain affected by the easiness in dynamic recovery and the processing temperature, and the degree of diffusivity which decides the grain growth.

\section{Conclusions}

As well as aluminum alloys, ultra-fine grained bulk steel (interstitial free (IF) steel) whose mean grain size is less than $1 \mu \mathrm{m}$ was successfully produced by Accumulative Roll-Bonding (ARB) process which has been developed by us as a novel intense straining process using rolling deformation. The ultra-fine grained IF-steel with mean grain size of $420 \mathrm{~nm}$ showed very large tensile strength of $870 \mathrm{MPa}$, which is 3.1 times larger than that of the starting material. The change in mechanical properties and the microstructural evolution in the course of ARB process were quite similar to those in the aluminum alloys previously studied. The present results indicate that ARB is very useful process for high straining 


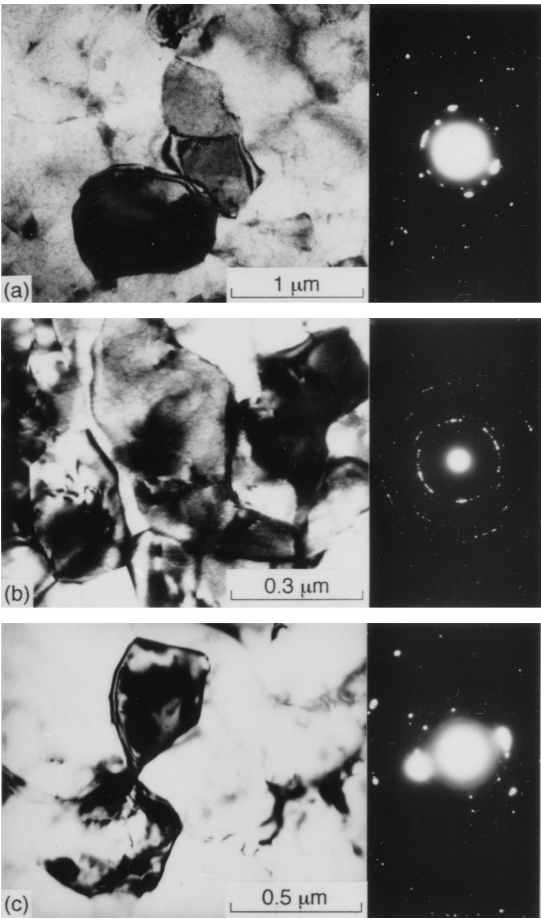

Figure 4. TEM microstructures showing the typical ultra-fine grains in the various materials. (a) 1100 commercial purity aluminum ARBed by 8 cycles at $473 \mathrm{~K}$. (b) 5083 Al-Mg alloy ARBed by 7 cycles at $473 \mathrm{~K}$. (c) IF steel ARBed by 7 cycles at $773 \mathrm{~K}$.

and ultra-grain refining, and most of structural metallic materials with ultra-fine grains could be easily achieved by ARB.

\section{Acknowledgment}

The authors wish to thank Mr. J. Miyamoto of Osaka University for his technical helps in practice of ARB process. This study was financially supported by the Grant-in-Aid for Basic Scientific Research (A) (1998) through the Ministry of Education, Science and Culture, Japan, and the alloy used in this study was supplied by NKK Co., Ltd. All those supports are greatly appreciated.

\section{References}

1. S. Takaki, Sanyo Technical Report 3.2 (1996).

2. A. K. Mukherjee, Materials Science and Technology, vol. 6, p. 407, VCH, Weinheim (1993).

3. T. G. Langdon, Key Eng. Mater. 97-98. 109 (1994).

4. B. Baudelet, J. Languillaume, and G. Kapelski, Key. Eng. Mater. 97-98, 125 (1994).

5. R. Z. Abdulov, R. Z. Valiev, and N. A. Krasilnikov, J. Mater. Sci. Lett. 9, 1445 (1990).

6. R. Z. Valiev, F. Chmelik, F. Bordeaux, G. Kapwlski, and B. Baudelet, Scripta Metall. Mater. 27, 855 (1992).

7. R. Z. Valiev, Yu.V. Ivanisenko, E. F. Rauch, and B. Baudelet, Acta Mater. 44, 4705 (1996).

8. R. Z. Valiev, N. A. Krasilnikov, and N. K. Tsenev, Mater. Sci. Eng. A137, 35 (1991).

9. R. Z. Valiev, A. V. Korznikov, and R. R. Mulyukov, Mater. Sci. Eng. A168, 141 (1993).

10. M. Furukawa, Z. Horita, M. Nemoto, R. Z. Valiev, and T. G. Langdon, Acta Mater. 44, 4619 (1996). 
11. R. Z. Valiev, E. V. Kozlov, Yu. F. Ivanov, J. Lian, A. A. Nazarov, and B. Baudelet, Acta Metall. Mater. 42 , 2467 (1994).

12. M. Furukawa, P. B. Berbon, Z. Horita, M. Nemoto, N. K. Tsenev, R. Z. Valiev, and T. G. Langdon, Mater. Sci. Forum, 233-234, 177 (1997).

13. Y. Kimura and S. Takaki, Mater. Trans. JIM. 36, 289 (1995).

14. K. Ameyama, M. Hiromitsu, N. Imai, O. Okada, and K. Nakata, Proceedings of Australian-Pacific Forum on Intelligent Processing and Manufacturing of Materials (IPMM 97), ed. T. Chandra, S. R. Leclair, J. A. Meech, B. Verma, M. Smith, and B. Balachandran, p. 982 (1997).

15. K. Ameyama, M. Hiromitsu, and N. Imai, Tetsu-to-Hagane 84, 357 (1998).

16. Y. Saito, H. Utsunomiya, N. Tsuji, and T. Sakai, Proceedings of the 6th International Conference on Aluminum Alloys (ICAA-6), Japan Institute of Light Metals, p. 2003 (1998).

17. Y. Saito, N. Tsuj, H. Utsunomiya, T. Sakai, and R. G. Hong, in Proceedings of the 6th International Conference on Aluminum Alloys (ICAA-6), Japan Institute of Light Metals, p. 1967 (1998).

18. Y. Saito, N. Tsuji, H. Utsunomiya, T. Sakai, and R. G. Hong, Scripta Mater. 39, 1221 (1998).

19. N. Tsuji, K. Shiotsuki, H. Utsunomiya, and Y. Saito, in Proceedings of the International Symposium on "Towards Innovation in Superplasticity-II," Trans Tech Publications.

20. H. Takechi, ISIJ Int. 34, 1 (1994).

21. Z. Horita, D. J. Smith, M. Furukawa, M. Nemoto, R. Z. Valiev, and T. G. Langdon, J. Mater. Res. 11, 1880 (1996). 